\title{
Positives and Negatives: Reconceptualising Gender Attributes within the Context of the Sex role Identity and Well-Being Literature: An Examination within the South African Context
}

\begin{tabular}{|c|c|}
\hline \multicolumn{2}{|c|}{$\begin{array}{l}\text { Authors: } \\
\text { Colleen Bernstein } 1 \\
\text { Ruksana Osman }\end{array}$} \\
\hline \multicolumn{2}{|c|}{$\begin{array}{l}\text { Affiliations: } \\
{ }^{1} \text { Department of Psychology, } \\
\text { School of Human and } \\
\text { Community Development, } \\
\text { University of the } \\
\text { Witwatersrand, South Africa }\end{array}$} \\
\hline \multicolumn{2}{|c|}{$\begin{array}{l}{ }^{2} \text { Faculty of Humanities, } \\
\text { University of the } \\
\text { Witwatersrand, South Africa }\end{array}$} \\
\hline \multicolumn{2}{|c|}{$\begin{array}{l}\text { Corresponding author: } \\
\text { Colleen Bernstein, } \\
\text { colleen.bernstein@wits.ac.za }\end{array}$} \\
\hline \multicolumn{2}{|c|}{$\begin{array}{l}\text { Dates: } \\
\text { Received: } 10 \text { Sept. } 2015 \\
\text { Accepted: } 16 \text { Nov. } 2015 \\
\text { Published: } 25 \text { May } 2016\end{array}$} \\
\hline \multicolumn{2}{|c|}{$\begin{array}{l}\text { How to cite this article: } \\
\text { Bernstein, C., \& Osman, R. } \\
\text { (2016). Positives and } \\
\text { negatives: Reconceptualising } \\
\text { gender attributes within the } \\
\text { context of the sex role } \\
\text { identity and well-being } \\
\text { literature: An examination } \\
\text { within the South African } \\
\text { context. SA Journal of } \\
\text { Industrial Psychology/SA } \\
\text { Tydskrif vir Bedryfsielkunde, } \\
\text { 42(1), a1309. http://dx.doi. } \\
\text { org/10.4102/sajip.v42i1.1309 }\end{array}$} \\
\hline \multicolumn{2}{|c|}{$\begin{array}{l}\text { Copyright: } \\
\text { (C) 2016. The Authors. } \\
\text { Licensee: AOSIS. This work is } \\
\text { licensed under the Creative } \\
\text { Commons Attribution } \\
\text { License. }\end{array}$} \\
\hline \multicolumn{2}{|l|}{ Read online: } \\
\hline 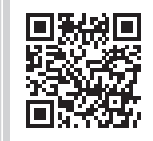 & $\begin{array}{l}\text { Scan this QR } \\
\text { code with your } \\
\text { smart phone or } \\
\text { mobile device } \\
\text { to read online. }\end{array}$ \\
\hline
\end{tabular}

Orientation: There is a lack of research examining both positive and negative sex-based traits and sex role identities. Previous research has predominantly focused on positive sex role identities and their relationship to various outcome variables. Findings for such research have not always been consistent. It has been argued that research that only examines positive identities is methodologically flawed and that the inconsistent findings in such research may be attributable to the fact that the research conducted has not examined the extent to which individuals may have adopted negative sex role identities.

Motivation for the study: With few exceptions, sex role identity (SRI) has been measured exclusively in terms of positive characteristics only. There is a dearth of research investigating both positive and negative sex role identities, particularly within the South African context.

Research purpose: The purpose of this research was to explore the extent to which individuals adopt both positive and negative sex-based traits and sex role identities. A theoretical argument is made for examining positive and negative gender attributes followed by a discussion of seven empirical studies, which demonstrate that significant proportions of samples are adopting negative sex role identities.

Research design, approach and method: This research was conducted using a cross-sectional design and a convenience sampling method across seven different samples. A total of 3462 employees participated in this research. A revised version of the Extended Personal Attribute Questionnaire (EPAQ-R) and a demographic survey were used to collect the data.

Main findings: Across all seven samples, a significant proportion of the respondents adopted negative sex role identities. These findings suggest that there is a need to measure both positive and negative identities in research on SRI. The proportion of respondents across the seven samples that adopted negative identities ranged from $44 \%$ to $49 \%$ whilst $46 \%$ to $54 \%$ indicated the adoption of positive identities.

Practical/managerial implications: This research is important as it highlights that investigations of SRI must assess both positive and negative sex role identities. Negative SRIs may have implications for critical individual and organisational outcomes. Furthermore, measures that assess both positive and negative identities may have implications for organisational processes, such as recruitment, selection and training, learning and development.

Contribution/value-add: The findings of this research contribute to the South African body of literature investigating sex role identities. The present study's finding of a high proportion of individuals endorsing negative identities has implications for future research. Future research needs to explore the relationship between both positive and negative identities and a wide variety of individual and organisational well-being indicators.

\section{Introduction}

In the past four decades there has been tremendous interest in and research on sex role identity (SRI) and individual and organisational well-being. However, this literature has been plagued with equivocal findings. Inconsistencies and contradictions may be attributable to the fact that research has only examined positive gender attributes ignoring the possible confounding influence of negative gender attributes (Wajsblat, 2011). The article by virtue of reviewing the appropriate literature and empirical findings across seven different samples argues that 
research needs to broaden the conceptualisation of SRI to include gender attributes that are positive and negative, or alternatively phrased, socially desirable and socially undesirable, to fully explore the relationship between SRI and well-being. The article outlines the central problem in the literature on SRI, that is, an approach in which only socially desirable, positive sex role identities are examined. It has been argued that whilst socially desirable positive identities may have positive implications for health and well-being, negative socially undesirable identities may not (Woodhill \& Samuels, 2003, 2004). Research that does not take into account these negative identities could mask or completely confound research findings that explore the well-being implications of positive identities only (Wajsblat, 2011). Evidence that has been counterintuitive or lacking in studies examining positive gendered attributes only may well be attributable to extraneous negative gender attributes and the extent to which they may be contributing to the variance in well-being indicators (Ghaed \& Gallo, 2006; Woodhill \& Samuels, 2003, 2004). In addition, research that does not measure negative identities fails to address the negative implications these identities may have on health and well-being indicators. The measurement of both positive and negative gender attributes may therefore be crucial in providing greater clarity with regard to findings within the SRI literature.

Consequently, the article proceeds to argue for broadening the SRI approach within the theoretical framework of the differentiated model, which encompasses both positive and negative gender attributes. Within the article, the empirical support for the argument is provided by findings obtained from seven different studies in the South African context $(n=3462)$. These findings indicated that almost half of each of the samples under study endorsed negative sex role identities. The discussion within the article focuses on implications of these findings for research on SRI and recommendations for future research are made.

\section{Literature review}

\section{An historical review of the research literature on SRI}

A vast research literature has developed since the 1970s, which indicates that SRI, that is, the sex role behaviours that individuals adopt as part of their gender identity have implications for well-being (Heilman, 2012). In this regard, research has described four identities, that is, the masculine identity, the feminine identity, the undifferentiated identity and the androgynous identity (Bem, 1975, 1981). The masculine identity describes individuals who have predominantly adopted masculine traits as part of the gender role identity with these individuals scoring high on masculine traits within inventories designed to measure SRI. Masculine traits are referred to within the literature as agentic or instrumental traits and examples of such traits are independence, assertiveness, competitiveness and decisiveness. Typically those who are masculine have an individualistic orientation, are capable of taking control and adopting leadership roles and are high on self-confidence, self-esteem and self-efficacy. The feminine identity describes individuals who have predominantly adopted feminine traits, scoring high on feminine items within sex role inventories. Femininity, interchangeably referred to in the literature as expressiveness or communion, contains within it traits such as helpfulness, warmth, caring for and concern for others, nurturance and kindness. Typically, those who are feminine are oriented towards communion with others and tend to be considerate towards and concerned for the welfare of others with whom they are engaged (Ghaed \& Gallo, 2006; Spence, Helmreich, \& Holahan, 1979; Spence, Helmreich, \& Stapp, 1975). The undifferentiated identity refers to those individuals who do not indicate any particular preference with regard to masculine and feminine traits and score low on both those identities (Bem, 1975, 1981). The androgynous identity, proposed by Bem to be the development ideal in terms of its implications for health and well-being, is a combination of both masculinity and femininity. In this respect, androgynous individuals have incorporated within their identity a balance of both masculine and feminine traits. Thus, the androgynous individual would have a high score on both masculine and feminine SRIs. The increased behavioural repertoire of traits that this implies would enable the androgynous individual to respond to and adapt to a wider range of situations and contexts depending on the behaviour required. An androgynous individual would therefore be able to be tough and assertive if so required by the situation but would also be able to show compassion and care if needed. It is specifically this ability to be able to draw on a wider range of behaviours, as required by varying situations and contexts, that enhances androgynous individuals' adaptational capacity (Bem, 1975; Woodhill \& Samuels, 2003, 2004).

Based on Bem's gender schema theory, a large body of research accumulated with androgyny proponents providing evidence of the numerous positive correlates of androgyny. For example, Cheng (2005) and May and Spangenburg (1997) found that those who were more androgynous had significantly more flexible coping styles in dealing with the environmental demands than those with other sex role orientations. Androgyny was also significantly correlated with greater creativity (Keller, Lavish, \& Brown, 2007), emotional intelligence (Guastello \& Guastello, 2003), selfesteem, achievement motivation, life satisfaction, marital satisfaction, subjective feelings of well-being (Norlander, Erixon, \& Archer, 2000), improved self-concept (Flaherty \& Dusek, 1980) and pro-social helping behaviour (Senneker \& Hendrick, 1983). In addition, the androgyny model achieved support in a range of applied settings, such as management (Jurma \& Powell, 1994; Lassk, Kennedy, Powell, \& Lagace, 1992), sales performance and marketing (Goolsby, Lagace, \& Boorom, 1992), psychotherapy (Cook, 1985; Petry \& Thomas, 1986) and education (Hébert, 2000). It was noted within all this research that what made androgynous individuals healthier was that they had a fuller behavioural repertoire because of their balance of masculine and feminine characteristics and they would therefore be able to engage in a fuller range of behaviours and responses to cues, such 
behaviours being dictated on a contingency basis by the specific needs of the situation and context (Woodhill \& Samuels, 2003, 2004).

\section{The development of SRI}

Adopting a social constructionist perspective, Bem's SRI approach noted that individuals' SRI developed as a function of socio-cultural expectations and the environmental context of the developing individual. This process of socialisation in terms of sex roles, which is based on biological sex, has generally been referred to as sex-typing (Eagly \& Wood, 2012; Park, 1997). Sex-typing as a process begins from the moment a child is born and is continued throughout early childhood into adulthood, leading to the entrenchment of gender stereotypes with regard to what men and women can or cannot do or should or should not do in terms of 'doing gender', that is in terms of what is 'prescribed' and what is 'proscribed' (Heilman, 2012; Prentice \& Carranza, 2002; West \& Zimmerman, 1987). Thus, if an individual is biologically male, society teaches this individual throughout all of his developmental stages to learn and master roles and appropriate behaviours that are associated with male and likewise for females. However, the SRI approach, although built on the foundations of prescribed stereotypes, also serves to explain the process that occurs when individuals do not totally conform to stereotypic norms of the prototype. In addition, the theory also engages with the issue of why some individuals adhere rigidly to stereotypes whilst others do not (Bernstein, 2013). Whilst masculine traits are typically and supposedly adopted by males - and likewise for feminine traits and females - the SRI literature specifically acknowledges that although masculine traits may be stereotypically prescribed for male and feminine traits may be stereotypically prescribed for female, this does not mean that biological males and females will only adopt prescribed, that is, sextyped traits as opposed to proscribed, that is, cross-typed traits. Depending on the social and cultural norms within which an individual is raised and the environment within which an individual resides, this will determine the extent to which biological males and biological females adopt and display traits that are only prescribed for their sex as opposed to traits that are proscribed, that is, designated for the opposite sex. In this regard, Bem $(1975,1981)$ notes that there are variations historically in terms of place, time and culture that determine the extent to which the behaviours, roles, attitudes and attributes that are prescribed for the sexes may deviate more or less from those that are traditional (that is sex-typed and prescribed). In other words, variations in terms of place, time and culture may cater for some latitude with regard to biological males and females adopting roles that are proscribed, that is non-traditional roles that have been traditionally assigned to the opposite sex. Bem (1981, p. 356) notes therefore that the gender or SRI developed and incorporated may include 'fuzzy sets' of behaviours, roles, attitudes and attributes organised around traditional male and female prototypes. This implies that there are degrees of variation in the roles that are culturally and socially constructed and that they are not always entirely stereotypic for each biological sex. As such, biological females may adopt masculine traits to a lesser or greater degree, biological males may adopt feminine traits to a lesser or greater degree or each of the sexes may adopt masculine and feminine traits equally. Variations in the broader socio-cultural environment - within the family structure, within the context of schooling and educators within the school environment, the religious community and/or within the context of individuals' extended family and/or peers - could determine the identities that are formed and the individuals' psychological relationship to these identities, that is, the individuals' acceptance or rejection of these identities and the extent to which they integrate them into their personality. Thus, socio-cultural variations could finally determine the SRI that individuals endorse and the range with which individuals' SRI becomes stereotypically masculine, stereotypically feminine or in any way retrotypic (Borna \& White, 2003; Hall, Gough, \& Seymour-Smith, 2012; Heilman, 2012; Littrell \& Nkomo, 2005).

\section{The masculinity model}

Although the androgyny model achieved a vast empirical base in support for its positive outcomes since its theoretical inception, a competing model with regard to what was the developmental ideal in relation to health and well-being was that of the masculinity model. In opposition to androgyny, adherents to the masculinity model proposed that those who were more masculine would enjoy the greatest level of health and well-being irrespective of whether they were biologically male or female. From the inception of androgyny as the proposed psychological ideal, opponents of this model primarily cited the negligible impact of femininity on overall well-being (Whitley, 1985). In this regard, the value of traditional male-oriented behaviours and traits as more socially desirable than those associated with femininity was highlighted with it being proposed that it is these maleoriented traits (evidenced within androgynous individuals) that actually account for the variance in well-being experienced by androgynous individuals (Dohi, Yamada, \& Asada, 2001; Heilman, 2012; Orlofsky \& O'Heron, 1987; Smiler, 2006). Based on this premise, many researchers attempting to explore the relation between SRI and wellbeing found extensive support for masculinity as compared to androgyny or femininity as the more adaptive SRI (Antill \& Cunningham, 1979; Cook, 1985; Dohi et al., 2001; Heilman, 2012; Kopper \& Epperson, 1996; Markstrom-Adams, 1989; Smiler, 2006; Whitley, 1985). These researchers thus argued that it is the masculinity component and not necessarily the combined balance of masculine and feminine traits that is the contributor to all the positive findings on health and well-being for androgyny. In a critical meta-analytic review of 35 studies examining the relation of SRI to self-esteem proposed to be the most widely used indicator of psychological well-being, findings most strongly supported the masculinity model (Whitley, 1985). Additional metaanalyses exploring the relation of sex role orientation to depression and general adjustment found similar support for masculinity as having the strongest relationship with better health (Bassoff \& Glass, 1982; Taylor \& Hall, 1982; 
Whitley, 1985). Subsequent findings have identified a number of psychological health correlates of masculinity, including work performance (Baril, Elbert, Mahar-Potter, \& Reavy, 1989; Jagacinski, 1987), resilience (Lam \& McBride-Chang, 2007), personal flexibility (Anderson, 1986), achievement (Adams \& Sherer, 1985) and improved psychological wellbeing (Castlebury \& Durham, 1997). The findings for the masculinity model thus provide the strongest empirical opposition to the adoption of androgyny as the most adaptive SRI (Wajsblat, 2011).

However, despite findings for the positive health effects of androgyny and masculinity, both the androgyny model and the masculinity model have not always provided consistent findings (Burchardt \& Serbin, 1982; Hanson \& Rayman, 1976; Lubinski, Tellegen, \& Butcher, 1981, 1983; O'Heron \& Orlofsky, 1990; Skoe, 1995; Wulff \& Steitz, 1999). In this regard, some studies have shown that androgyny does not have the greatest health effects as purported and at times may even indicate poorer health effects as compared to masculinity and femininity. Similarly, some studies promoting the masculinity model have shown that masculinity demonstrates poorer health effects as compared to androgyny and femininity.

It has been argued that inconsistent findings for both the androgyny model and the masculinity model may be attributable to the fact that research using these models has only examined positive socially desirable sex-based traits. Since the 1980s, an ever-increasing sub-group of researchers on SRI have suggested that the construct consists of more dimensions than originally proposed and have argued for distinguishing or differentiating between socially desirable (positive) and undesirable (negative) gender role traits (Athenstaedt, 2003; Berger \& Krahe, 2013; Bernstein, 2013; McCreary \& Korabik, 1994; Ricciardelli \& Williams, 1995; Spence et al., 1975; 1979; Wajsblat, 2011; Woodhill \& Samuels, 2003, 2004). These researchers note that in the event of negative attributes being present, and their contribution not being assessed, this could confound research findings. In this regard, a differentiated model that enables the examination of both positive and negative gendered attributes has been proposed (Berger \& Krahé, 2013; Wajsblat, 2011; Woodhill \& Samuels, 2003, 2004).

Within this model, as with previous models that only describe and assess positive gender attributes, positive masculine attributes are, for example, ambition, competitiveness, assertiveness and decisiveness, whilst examples of positive feminine attributes are consideration, helpfulness, warmth, compassion and tolerance. Positive androgyny is evident when both positive masculine and feminine attributes are displayed. However, this model also includes negative gender attributes with negative masculine attributes being, for example, aggression, hostility and authoritarianism, whilst negative feminine traits are, for example, anxiety, being overly worried, whiny and nagging. Negative androgyny would consist of a combination of both negative masculine and negative feminine traits. Thus, research that only examines positive traits and does not measure the possible existence of negative traits could have the findings confounded if negative traits are evident and in fact are dominant.

\section{The differentiated model}

Based on the inconsistencies within previous research on SRI, which has only measured socially desirable positive sex-based traits, Woodhill and Samuels (2003, 2004) have argued for the adoption of a differentiated model and have proposed that there are seven categories of sex role identities: positive masculinity, negative masculinity, positive femininity, negative femininity, positive androgyny, negative androgyny and the undifferentiated identity. According to this model, one could be predominantly positively masculine if one adopted a high degree of positively masculine traits or predominantly negatively masculine if one adopted a high degree of negatively masculine traits. Similarly, one could also be predominantly positively feminine or predominantly negatively feminine. To the extent that one adopted a high degree of both positive masculine and positive feminine traits, one would be categorised with a positively androgynous SRI. Alternatively, the adoption of a high degree of both negative masculine and negative feminine traits would identify the individual concerned as having a negatively androgynous identity. If one scored low on positive and negative masculinity and positive and negative femininity one would be categorised as undifferentiated. Typically, negative masculinity, interchangeably referred to in the literature as unmitigated agency or unmitigated instrumentality, evidences behavioural traits of hostility, aggressiveness, dictatorial authoritarian behaviour, an excessive tendency towards self-enhancement and a complete disregard or extremely low regard for the welfare of others. Typical negatively feminine traits, referred to as unmitigated communion or unmitigated expressiveness within the literature, are those of being overly submissive, passive, anxious, excessively worried, dependent, fearful and also overly concerned with the welfare of others to the detriment of one's own well-being. In this regard, there is a lack of concern for one's self and an excessive concern with placing the needs of others before one's own needs are met (Aube, 2008; Bakan, 1966; Fritz \& Helgeson, 1998; Ghaed \& Gallo, 2006; Helgeson, 1994; Helgeson \& Fritz, 1998, 1999). With regard to androgyny, the positively androgynous individual could demonstrate high levels of independence (positive masculinity), compassion (positive femininity), ambition (positive masculinity) and/or tolerance (positive femininity), whereas a negatively androgynous person could demonstrate high levels of submissiveness (negative femininity) and selfishness (negative masculinity), be overly anxious (negative femininity) and/or aggressive (negative masculinity). As previously mentioned, androgynous people are supposed to have a fuller behavioural repertoire in that they are, because of their balance between masculine and feminine characteristics, able to engage in a fuller range of behaviours and responses to environmental cues. However, if an individual 
is negatively androgynous, they would have a wider range of negative behaviours and responses to cues and a bigger repertoire of undesirable behaviours from which to choose a response (Woodhill \& Samuels, 2003, 2004). As such, they may, for example, react in an undesirable feminine way in one situation (e.g. submissively) and in an undesirable masculine way in another situation (e.g. aggressively). Consequently, it becomes clear that categories of masculinity, femininity or androgyny, which are confined to positive aspects only, cannot capture these important differences because such categories, by definition, ignore genderassociated 'vices', that is, failings and deficits of negatively gendered traits (Woodhill \& Samuels, 2003, 2004).

However, a major obstacle that has remained in stimulating research on both desirable and undesirable aspects of SRI pertains specifically to a limited number of measures that assess both positive and negative attributes and the poor psychometric properties of these instruments, particularly pertaining to the internal consistency reliability of these instruments. Although a small number of instruments do exist, for example, Extended Personal Attribute Questionnaire (EPAQ) by Spence et al. (1975, 1979; Helmreich, Spence \& Wilhelm, 1981); Australian Sex Role Inventory by Antill et al. $(1981,1984)$ and Unmitigated Communion Scale by Helgeson et al. (1994, 1998), all these instruments have demonstrated poor internal consistency reliability. More specifically, all negative sub-scales within these instruments (negative masculinity and negative femininity) have demonstrated poor internal consistency. In this regard, internal consistencies for sub-scales have ranged below 0.60 and at times are lower than 0.50. Therefore, whilst some research has been carried out, which has reported differences between positive and negative identities, for example, Marsh and Myers (1986), Wajsblat (2011), Woodhill and Samuels (2003) and Yawn (2007), their usage of these instruments may cast some doubt upon their findings.

More recently, Berger and Krahe (2013) have developed an instrument that measures both positive and negative sex role identities and demonstrates adequate psychometric properties. However, this instrument has been developed for native German speakers and therefore cannot be used on English-speaking populations.

\section{The South African research project}

Based on the arguments for a differentiated model, and the limitations of previous instrumentation, a research project was undertaken within South Africa. The intention of this project was (1) to revise the EPAQ to develop an instrument that demonstrates adequate internal consistency, that is, subscales that report internal consistencies higher than 0.70 , as required in the social sciences (Nunnally \& Bernstein, 1994) and (2) to determine the extent to which individuals are endorsing positive identities and negative identities in the samples under study to ascertain whether there is indeed a need to measure both positive and negative SRIs. Seven studies were included within the project. The research approach, research participants, research procedure, measuring instrument and statistical analysis are described below.

\section{Research design Research approach}

All the seven studies used an empirical research design. In addition, a quantitative survey methodology was used to collect data from the samples within the 10 studies. The collection of data was also cross-sectional as it entailed data collection from several groups of participants at a single point in time. As SRI is regarded to be crystallised by the time the individual reaches early adulthood (Gerdes, Moore, Ochse, \& van Ede, 1988), the use of a cross-sectional approach was deemed to be appropriate.

\section{Research participants}

The data were collected by means of convenience sampling. The research participants consisted of white-collar employees from a wide variety of South African organisations. Participants were sampled across seven different studies with the total sample consisting of 3462 respondents. The majority of the sample were women, white and English speaking. In addition, most of the sample were aged between 25 and 35 years of age, were married and possessed a Matriculation Certificate. A full description of the sample is provided in Table 1.

\section{Research procedure}

With regard to respondents, the Human Resource Directors of various organisations were approached to be part of the study. Respondents were sampled from the insurance and

TABLE 1: Demographics of total sample $(n=3462)$.

\begin{tabular}{|c|c|c|c|}
\hline Variable & Category & $f$ & $\%$ \\
\hline \multirow[t]{5}{*}{ Age } & $18-25$ & 130 & 3.75 \\
\hline & $26-35$ & 1557 & 44.91 \\
\hline & $36-45$ & 1331 & 38.44 \\
\hline & $46-55$ & 360 & 10.39 \\
\hline & $56-65$ & 84 & 2.42 \\
\hline \multirow[t]{2}{*}{ Biological sex } & Women & 2531 & 73.10 \\
\hline & Men & 931 & 26.901 \\
\hline \multirow[t]{5}{*}{ Population group } & Black & 810 & 23.39 \\
\hline & White & 1451 & 41.91 \\
\hline & Mixed-race & 620 & 17.90 \\
\hline & Asian & 530 & 15.30 \\
\hline & Missing & 51 & 1.50 \\
\hline \multirow[t]{3}{*}{ Language } & English & 1741 & 50.28 \\
\hline & Afrikaans & 983 & 28.39 \\
\hline & African Language & 738 & 21.33 \\
\hline \multirow[t]{6}{*}{ Level of education } & Less than Matric & 67 & 1.93 \\
\hline & Matric & 1439 & 41.57 \\
\hline & Post-Matric diploma & 935 & 27 \\
\hline & Degree & 858 & 24.78 \\
\hline & Postgraduate degree & 77 & 2.24 \\
\hline & Missing & 86 & 2.48 \\
\hline \multirow[t]{5}{*}{ Marital status } & Single & 852 & 24.61 \\
\hline & Married & 1681 & 48.57 \\
\hline & Cohabiting & 184 & 5.31 \\
\hline & Divorced & 698 & 20.16 \\
\hline & Widowed & 47 & 1.35 \\
\hline
\end{tabular}

$f$, frequency. 
banking sector, the manufacturing sector, professional firms (law and accounting) and the tertiary education sector. Once written permission from the various directors of human resources was obtained, the research project commenced. A letter explaining the objective of the survey and requesting potential participation in the survey was then sent electronically to employees within the organisations. The email provided the potential participants with a secure encrypted link through which they could access the survey. On accessing the link, potential participants were presented with a questionnaire in which they were required to record their biographical information and were then provided with instructions as to how to fill in the survey. Ethical considerations were taken into account with all potential participants being informed that their participation was voluntary and that they would not be advantaged or disadvantaged in any way by choosing to participant or not to participate. Potential participants were informed that by completing and submitting the survey, they were deemed to be providing consent to participate. However, they were also informed that before submitting the survey, they could withdraw at any time by not completing and/or not submitting the survey. Potential participants were also informed that they were not required to provide any identifying information, that no-one other than the researchers would have access to their responses. In addition, they were informed that the results of the survey would be reported as a summary of general trends thus ensuring that no single individual could be identified. Although the participants' IP addresses was recorded by filling in the survey, once the data were downloaded into an Excel spreadsheet, all IP addresses were deleted.

Consequently, the ethical considerations of voluntary participation, informed consent, anonymity and confidentiality were deemed to have been met. The email addresses of the researchers were provided so that participants could contact the researchers if they required any further information regarding the research.

\section{Measuring instrument}

SRI was measured using a revised version of the original EPAQ developed by Spence et al. (1975). The revised version was developed by Bernstein (2013) and reported acceptable psychometric properties. For example, the original EPAQ reported internal consistencies of 0.73 for positive masculinity, 0.76 for positive femininity, 0.59 for negative masculinity and 0.46 for negative femininity. In the revised version (EPAQ-R), internal consistencies across all seven studies were significantly higher and are discussed in the results section and reported in Table 4.

The EPAQ-R consisted of 12 positively feminine items, 12 positively masculine items, 18 negatively feminine items, and 16 negatively masculine items. Items were scored on a scale ranging from 1-5, where higher scores indicated greater agreement with the item. Scores on items within sub-scale were summed to obtain a total score for each sub-scale, that is, a total score for positive femininity, negative femininity, positive masculinity and negative masculinity. Respondents were asked to indicate the degree to which they felt each item described them. Examples of negative masculine items were Not at all aggressive (1) to Very aggressive (5) and Not at all hostile (1) to Very hostile (5). Examples of negative feminine items were Not at all submissive (1) to Very submissive (5) and Not at all easily hurt (1) to Very easily hurt (5). Examples of positive masculine items were Not at all competitive (1) to Very competitive (5) and Not at all daring (1) to Very daring (5). Examples of positive feminine items were Not at all kind-hearted (1) to Very kind-hearted (5) and Not at all warm in relation to others (1) to Very warm in relation to others (5). As proposed by Woodhill and Samuels (2003), to make valid, statistical comparisons between positive and negative raw scores, all scores were converted into z-scores. Respondents were then classified into one of the seven possible SRI categories, namely positively androgynous, negatively androgynous, positively feminine, negatively feminine, positively masculine, negatively masculine or undifferentiated. Androgynous participants were determined by a relative balance of positive feminine and positive masculine qualities or a balance of negative feminine and negative masculine qualities. Those with high scores (a pair of $z$-scores above zero which acted as the standardised sample mean) on both positive masculinity and positive femininity were categorised as positively androgynous, whilst those with high scores on both negative masculinity and negative femininity were categorised as negatively androgynous. As the more negative a $z$-score gets, the lower its association with the raw score, therefore, those remaining non-androgynous participants were classified as positively feminine; negatively feminine, positively masculine or negatively masculine, according to which of their $z$-scores on these sub-scales had the highest positive value.

\section{Research method}

\section{Statistical analysis}

Data were analysed using Microsoft Excel and SAS Enterprise Guide Program Version 5. To test our argument that research needs to measure both positive and negative SRIs, we used the $z$-score method within all seven studies to determine how many individuals within each sample were endorsing positive identities and how many were endorsing negative identities. Using this method, respondents were categorised into one of the positive identities (positively masculine, or positively feminine, or positively androgynous) or one of the negative identities (negatively masculine, or negatively feminine, or negatively androgynous). If a respondent scored low on all these possible identities, they would be categorised as undifferentiated. As mentioned, this method proposed by Woodhill and Samuels $(2003,2004)$ notes that those with high scores (a pair of $z$-scores above zero which acted as the standardised sample mean) on both positive masculinity and positive femininity were categorised as positively androgynous, whilst those with high scores on both negative masculinity and negative femininity were categorised as negatively androgynous. As the more negative a z-score gets, 
the lower its association with the raw score; therefore, those remaining non-androgynous participants were classified as positively feminine, negatively feminine, positively masculine or negatively masculine, according to which of their $z$-scores on these sub-scales had the highest positive value.

\section{Descriptive statistics}

Before this analysis, the data were screened for normality. Means, standard deviations and skewness were determined to describe the data. For all seven studies, a cut-off point of 2.00 was set for skewness and 4.00 for kurtosis to ensure that the data were normally distributed (Huck, 2009).

\section{Internal reliability of the EPAQ-R}

Internal reliability was assessed by determining the Cronbach's alpha for all sub-scales of the EPAQ-R within all seven studies. The reliability of an assessment instrument or measure is defined by its consistency, accuracy, dependability, precision and freedom from measurement error (Anastasi, 1982). To ensure an accurate reflection of the data, it is necessary to confirm that no measurement error exists. Whilst it may be impossible to completely eliminate all measurement errors, there is still a need to assess the extent to which measurement error does exist. More specifically, Cronbach's alpha is a measure of the degree of homogeneity of test items, that is, the degree to which items are positively inter-correlated and thus measure the same construct. This measure of reliability assesses the degree to which the different parts of the subscales, that is, items within the sub-scales measure the same construct, by calculating inter-item correlations (Murphy \& Davidshofer, 2005). Within the social sciences, 0.60 is regarded to be an acceptable level of internal consistency (Kim \& Mueller, 1986); however, the more rigorous level of 0.70 as proposed by Nunnally and Bernstein (1994) was adopted in the present study.

\section{Independence of sub-scales}

To confirm that positive masculinity, negative masculinity, positive femininity and negative femininity represented independent sub-scales, Pearson's correlations between the four sub-scales were also conducted. Findings for sub-scale correlations are reported in Table 4. Whilst theoretically it was expected that there would be some inter-correlation between the sub-scales, the degree of inter-correlation should not be too high so as to indicate that the sub-scales are all measuring the same construct (Berger \& Krahe, 2013; Spence et al., 1975, 1979). (These theoretical expectations are discussed in detail within the Results section.)

\section{Results}

\section{Descriptive statistics}

Table 2 shows the results for the mean, standard deviation, skewness and kurtosis of the combined sample $(n=3462)$.
TABLE 2: Descriptive statistics.

\begin{tabular}{lcccc}
\hline Variable & M & SD & Skewness & Kurtosis \\
\hline 1 Positive masculinity & 47.48 & 7.94 & -0.27 & -0.21 \\
2 Negative masculinity & 35.38 & 8.26 & 0.21 & 0.46 \\
3 Positive femininity & 48.81 & 6.33 & 0.43 & 0.38 \\
4 Negative femininity & 42.39 & 7.05 & -0.07 & -0.32 \\
\hline
\end{tabular}

$\mathrm{SD}$, standard deviation; $\mathrm{M}$, mean.

These results indicate that the data were normally distributed.

\section{Internal reliability of the EPAQ-R}

Table 3 reports the internal consistency of the four sub-scales across each of the seven studies. It is evident that in all seven studies the internal consistency of the four sub-scales reported satisfactory internal consistencies, that is, internal consistencies above 0.70 (Nunnally \& Bernstein, 1994).

\section{Independence of sub-scales}

Table 4 reports the correlations between sub-scales across all seven studies $(n=3462)$. These correlations indicate that the four sub-scales are relatively independent of one another and that theoretically correlations are in the expected direction.

Same-sex positive and negative scales had low positive correlations. For example, $\mathrm{M}+$ and $\mathrm{M}-$ had a low positive correlation with each other (0.16), and F+ and F- had low positive correlation with each other (0.13). In addition, a low positive correlation was obtained between the positive crosstype sex scales, that is, $\mathrm{M}+$ and $\mathrm{F}+$ correlation was 0.03 . Significant inverse correlations were seen between the positive and negative cross-sex-typed scales. In the present study, the correlation between positive masculinity and negative femininity was -0.42 . There was also positive but low correlation of 0.20 between negative masculinity and negative femininity.

\section{Results of categorisation}

Once the instruments' internal consistency of the EPAQ-R had been assessed by determining Cronbach's alpha coefficients across all seven studies for each of the sub-scales and an inspection of the inter-scale correlations had shown

TABLE 3: Cronbach's alphas for each of the seven studies.

\begin{tabular}{|c|c|c|c|c|c|c|c|}
\hline $\bar{\alpha}$ & Study 1 & Study 2 & Study 3 & Study 4 & Study 5 & Study 6 & Study 7 \\
\hline Positive masculinity & 0.80 & 74 & 0.83 & 0.82 & 0.80 & 0.82 & 0.79 \\
\hline Negative masculinity & 0.84 & 0.86 & 0.88 & 0.86 & 0.86 & 0.83 & 0.78 \\
\hline Positive femininity & 0.83 & 0.80 & 0.88 & 0.79 & 0.83 & 0.83 & 0.79 \\
\hline Negative femininity & 0.80 & 0.71 & 0.90 & 0.86 & 0.85 & 0.84 & 0.78 \\
\hline
\end{tabular}

TABLE 4: Sub-scale correlations across total sample.

\begin{tabular}{lcccc}
\hline Variable & $\mathbf{1}$ & $\mathbf{2}$ & $\mathbf{3}$ & $\mathbf{4}$ \\
\hline 1 Positive masculinity & - & - & - & - \\
2 Negative masculinity & 0.16 & - & - & - \\
3 Positive femininity & 0.03 & -0.38 & - & - \\
4 Negative femininity & -0.42 & 0.20 & 0.13 & - \\
\hline
\end{tabular}


that the four sub-scales were relatively independent of one another and were aligned to theoretical expectations, the categorisation of individuals into the different SRIs using the $z$-score method was undertaken.

Based on the z-score method, a table of the percentages of positive versus negative identities within each study is represented in Table 5. Positive identities consist of positive androgyny, positive masculinity and positive femininity. Negative identities consist of negative androgyny, negative masculinity and negative femininity. Findings with regard to percentages indicated that within all these studies between $42 \%$ and $48 \%$ of individuals were categorised with negative identities, providing a strong argument for the use of the differentiated model.

The percentages and frequencies of respondents within all seven samples endorsing positive identities and negative identities are displayed in Table 5.

An overview of the data presented in Table 5 suggests that each sample under study indicates that within Study 1 negative identities were adopted by 664 of 1477 respondents (45\%). In Study 2, negative identities were adopted by 38 of 81 respondents (47\%), and in Study 3, negative identities were adopted by 189 of 412 respondents (46\%). In Study 4, negative identities were adopted by 83 of 177 respondents (47\%), and in Study 5, negative identities were adopted by 291 of 595 respondents (49\%). In Studies 6 and 7, negative identities were adopted by 234

TABLE 5: Percentages of positive, negative and undifferentiated identities within each study.

\begin{tabular}{lcccc}
\hline Study & $\boldsymbol{N}$ & $\begin{array}{c}\text { Positive SRIs } \\
\mathbf{( \% )}\end{array}$ & $\begin{array}{c}\text { Negative SRIs } \\
\mathbf{( \% )}\end{array}$ & $\begin{array}{c}\text { Undifferentiated } \\
\mathbf{( \% )}\end{array}$ \\
\hline Study 1 & 1477 & 50 & 45 & 5 \\
Study 2 & 81 & 52 & 47 & 1 \\
Study 3 & 412 & 47 & 46 & 7 \\
Study 4 & 177 & 46 & 47 & 7 \\
Study 5 & 595 & 50 & 49 & 1 \\
Study 6 & 478 & 50 & 49 & 1 \\
Study 7 & 251 & 50 & 46 & 4 \\
\hline Totals & & $\mathbf{4 9 . 3}$ & $\mathbf{4 7}$ & $\mathbf{3 . 7 1}$ \\
\hline
\end{tabular}

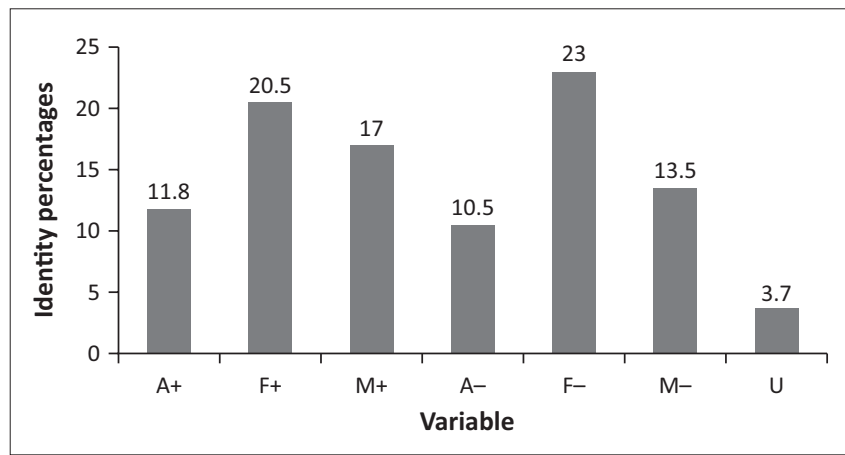

FIGURE 1: Of the combined sample ( $n=3462), 11.8 \%$ were positively androgynous $(A+), 20.5 \%$ were positively feminine and $17 \%$ were positively masculine $(F+)$. With regard to negative identities, $10.5 \%$ were negatively androgynous, $23 \%$ were negatively feminine and $13.5 \%$ were negatively masculine. The undifferentitated category constituted $3.7 \%$. The total for negative identities was $47 \%$, whilst the total for positive identities was $49.3 \%$. of 478 respondents and 115 of 251 respondents, respectively (49\% and 46\%) (Figure 1).

\section{Discussion}

The current study proposed a broadening of the conceptualisation of SRI to include not only positive desirable attributes but also negative undesirable attributes. The study was motivated by a number of previous researchers that have argued that, on conceptual grounds, SRI includes both positive and negative attributes (Athenstaedt, 2003; Berger \& Krahe, 2013; Bernstein, 2013; McCreary \& Korabik, 1994; Ricciardelli \& Williams, 1995; Spence et al., 1975, 1979; Wajsblat, 2011; Woodhill \& Samuels, 2003, 2004). This argument has been largely disregarded in research conducted previously, with virtually all research measuring positive attributes only. It is this disregard which may account for inconsistencies in previous research on the health benefits of masculinity and androgyny. Studies that have failed to show the proposed health benefits of masculine or androgynous SRIs may possibly have had their findings masked by the presence of negative gendered attributes, which were not being recorded by the assessments used (Berger \& Krahé, 2013; Wajsblat, 2011; Woodhill \& Samuels, 2003, 2004).

Whilst the conceptual argument proposed for assessing both positive and negative gendered attributes has been sound, there has been a distinct lack of research that has explored the extent to which individuals are adopting negative SRIs. This lack of research may largely be attributable to the fact that there has also been a lack of instrumentation that could be used to measure both positive and negative attributes (Bernstein, 2013). Some research has been carried out which has provided evidence of the existence of both positive and negative SRIs within samples under study and which, in addition, has noted that positive and negative attributes have differential associations with aspects of well-being (Marsh \& Myers, 1986; Wajsblat, 2011; Woodhill \& Samuels, 2003; Yawn, 2007). However, the findings of this research may be cast into some doubt as the instruments used within this research have not demonstrated adequate psychometric properties, particularly with regard to internal consistencies of sub-scales measuring positive and negative identities (Bernstein, 2013).

In this regard, the current study used a revised instrument, referred to as the EPAQ-R, and reported internal consistencies across seven different samples that ranged from between 0.74 and 0.83 for positive masculinity, between 0.78 and 0.88 for negative masculinity, between 0.79 and 0.88 for positive femininity and between 0.71 and 0.90 for negative femininity. The patterns of inter-correlations in the current study were aligned to theoretical expectations as proposed by Helmreich, Spence, and Wilhelm $(1981)$ and Spence et al. $(1975,1979)$ and similar to those reported more recently by Berger and Krahe (2013). Negative and positive masculinity were expected, and found, to be correlated to some extent as both sets of traits are considered to be those more stereotypically 
displayed by males; but they differ in terms of whether they would be regarded to be socially desirable or socially undesirable (Helmreich et al., 1981; Spence et al., 1975, 1979). Negative and positive femininity were also expected, and found, to be correlated to some extent as they are both considered to be traits more stereotypically displayed by females, but again, they would differ in terms of their social desirability (Helmreich et al., 1981; Spence et al., 1975, 1979). Positive masculinity, which represents a cluster of traits associated with competency and high levels of self-esteem and well-being, had a strong negative correlation with negative feminine traits, which represent a cluster of traits associated with anxiety, neuroticism and low well-being and is in line with research (Helmreich et al., 1981; Spence et al., 1975, 1979). Lastly, negative masculine traits, which represent an unmitigated level of aggression, power, dominance and egocentrism, had a strong negative correlation with positive femininity, which represents a set of traits high on concern for others such as caring and helpfulness and an interest in the welfare of others - also in line with literature (Helmreich et al., 1981; Spence et al., 1975, 1979).

In terms of the exploration of the extent to which individuals were endorsing negative identities and positive identities to justify usage of the differentiated model within future research on SRI, findings in the present study indicated that these negative identities are indeed evident with a significant proportion of respondents sampled endorsing them. Across the seven samples that were studied $(n=3462), 10.5 \%$ of the samples were negatively androgynous; $23 \%$ were negatively feminine and $13.5 \%$ were negatively masculine. Thus, almost half of the individuals, that is, $47 \%$, endorsed negative identities. Furthermore, a sufficiently broad range of respondents were sampled in terms of age, population group, gender and educational level and these sample sub-groups were of sufficient size to suggest that these findings may be generalisable to the wider population.

However, in spite of the evidence provided, the study is limited in that it does not examine the implications of these negative identities for individual and organisational well-being. This particular limitation is discussed below along with practical implications and recommendations for future research.

\section{Limitations of the present study and recommendations for future research}

The main limitation of the present research pertains to whether negative identities would predict different outcomes as compared to positive identities. Whilst some international research has been carried out that has indicated that there are differences in well-being indicators for those who have positive SRIs as compared to those who have negative SRIs, research on these differences within the South African context have been, to the authors' knowledge, non-existent. In particular, there has been no research within South Africa on the implications of negative SRIs for individual and organisational outcomes.
Whilst there is a vast body of literature on the relationship between positive identities and outcome variables of selfesteem, perceptions of work stress, leadership abilities and leadership success (Appelbaum, Audet, \& Miller, 2003; Powell \& Butterfield, 2015; Rawski, Djurdjevic, \& Sheppard, 2014; Vinnicombe \& Singh, 2002; Wolfram \& Gratton, 2014), there has been little or no research on the implications of negative identities for well-being particularly in relation to organisational well-being (Wajsblat, 2011; Woodhill and Samuels, 2003, 2004). Future research thus needs to crucially address this gap to determine what the implications of are of such negative identities for both individuals and the organisations within which they are employed.

At present, research is underway that explores the relationship between positive identities and negative identities and a number of individual and workplace outcomes, such as psychological health and well-being, perceived work stress, self-esteem at work, self-efficacy at work, hope, resilience, emotional intelligence, work engagement, social support at work, job satisfaction and organisational commitment. If such research yields findings that suggest that negative identities are indeed associated with poor individual health and organisational outcomes, these findings may in turn have far-reaching implications for the purpose of recruitment, selection and training within the work context. Consequently, the present study's findings, which indicate that there is evidence of individuals' endorsing negative identities, need to be further interrogated by future research using the differentiated model in the South African workplace context.

Another limitation of the present study is that it has not explored whether relationships exist between demographic characteristics and socio-cultural contexts and the endorsement of positive and negative SRIs. Whilst research has examined the relationship between a number of demographic characteristics and cultural contexts and the adoption of positive SRIs (Snyman, 2011), there has been a dearth of research on the relationship between these variables and the adoption of negative SRIs. It is noted that whilst almost half the respondents sampled within the present study endorsed negative identities, just over half of the respondents endorsed positive identities. As it is proposed that SRI is socially constructed and as positive identities are regarded to be 'healthier', future research needs to be carried out to determine what demographic and/or social factors may foster the adoption of positive socially desirable identities and what factors may promote the adoption of socially undesirable negative identities.

\section{Practical implications of the present study}

Findings of the present research may have a number of practical implications for organisations. If future research, as has some previous research (Berger \& Krahé, 2013; Marsh \& Myers, 1986; Wajsblat, 2011; Woodhill \& Samuels, 2003; Yawn, 2007), demonstrates that there are indeed differential associations with well-being for positive and negative identities, then this will have implications for organisations. These implications may be 
pertinent in relation to the recruitment, selection and placement of individuals within organisations. In addition, from a practical perspective, assessment of individuals' SRI profiles may have implications for training and development and counselling interventions within the workplace.

With regard to recruitment and selection, the identification of individuals with negative SRIs could serve as a screening tool to avoid appointing individuals whose negative traits could have negative implications for their ability to function adequately if not optimally within a particular position (Jacobs, 2014). For individuals already within employment, to the extent that their negative traits could be impacting negatively on their ability to function within their jobs so could counselling interventions be put into place to help them manage these traits more effectively. Training and development could also be used for individuals in an attempt to foster and promote the development of more positive traits within individuals, especially when such traits are aligned with the values and culture of the organisation and thereby the desired behaviours that the organisation wishes to manifest (Jacobs, 2014). Examples of this may be seen in certain professions such as nursing and teaching, where feminine values of compassion, concern for others and caring are promoted. In organisations where the culture is one of competition and aggressiveness within the markets and where more masculine values are likely to be favoured, training and development could be more geared towards fostering masculine values and behaviours.

There has been to the authors' knowledge, no research carried out, on using SRI instruments for such practical purposes within organisations and, therefore, the efficacy of such use remains to be explored in future research.

\section{Conclusion}

The mixed results of SRI and well-being research may be attributable to the fact that these studies have ignored the assessment of negative gendered attributes and their relationship to well-being. Studies that simply examine whether individuals are positively androgynous, positively masculine, positively feminine or undifferentiated clearly ignore the myriad differences that may be evident within each sex, specifically with regard to the possible presence of negative gendered attributes. Wajsblat (2011) argues that 'the inability of prior research to differentiate between the positive and negative types of androgyny could have been responsible for masking the benefits of positive androgyny' (p. 563). This proposition can be applied to all research on SRI that has failed to consider the presence of negative socially undesirable traits within individuals. These mixed findings which suggested a lack in the theoretical understanding of different sex roles thus prompted the need for a broader examination of the construct, using the differentiated model within the present study. Results of the present study suggest that a significant proportion of respondents in each of the seven samples studied were categorised with negative identities. The extent of the presence of negative SRIs within the present study suggests that research cannot abdicate their measurement and lends support to the argument that research on SRIs that assesses both desirable and undesirable SRIs warrants further investigation. The present study's findings add to the literature on SRI in the South African context and provide a basis for researchers to build upon in the future. The research field of SRI will be greatly enhanced if future studies examine the relationship of both positive and negative sex role identities to outcome variables and the explore the influence of demographic characteristics and contextual factors in the adoption of positive or negative sex role identities.

\section{Acknowledgements Competing interests}

The authors declare that they have no financial or personal relationships which may have inappropriately influenced them in writing this article.

\section{Authors' contributions}

Part of this data was collected by C.B. for her Doctor of Philosophy degree. The data collected for the remaining nine studies collected by Honours and Masters students as part of a research project to examine the adoption of positive and negative sex role identities amongst South African samples. C.B. was primarily responsible for the supervising of the data collection and the management of the data. In addition, C.B. was solely responsible for writing the literature review, analysing the data of the overall sample, and presenting the results and discussing the implications within the present manuscript. All students provided written consent that the data collected within their research could be utilised within the present study. R.O. acted as supervisor to C.B. for her $\mathrm{PhD}$ and was involved in making recommendations and reading and editing of the manuscript.

\section{References}

Adams, C., \& Sherer, M. (1985). Sex-role orientation and psychological adjustment Implications for the masculinity model. Sex Roles, 12(11-12), 1211-1218.

Anastasi, A. (1982). Psychological testing. (5th edn.). New York, NY: Macmillan.

Anderson, K. (1986). Androgyny, flexibility, and individualism. Journal of Personality Assessment, 50(2), 265-278.

Antill, J.K., \& Cunningham, J.D. (1979). Self-esteem as a function of masculinity in both sexes. Journal of Consulting and Clinical Psychology, 47(4), 783-785.

Antill, J., Cunningham, J., Russell, G., \& Thompson, N. (1981). An Australian Sex Role Scale. Australian Journal of Psychology, 33, 169-183.

Appelbaum, S.H., Audet, L., \& Miller, J.C. (2003). Gender and leadership? Leadership and gender? A journey through the landscape of theories. Leadership \& Organization Development Journal, 24(1), 43-51.

Athenstaedt, U. (2003). On the content and structure of the gender role self-concept: Including gender stereotypical behaviors in addition to traits. Psychology of Women Quarterly, 27(4), 309-318.

Aube, J. (2008). Balancing concern for other with concern for self: Links between unmitigated communion, communion, and psychological well-being. Journal of Personality, 76(1), 101-133.

Bakan, D. (1966). The duality of human existence: An essay on psychology and religion. Oxford England: Rand McNally, Ballard.

Baril, G.L., Elbert, E., Mahar-Potter, S., \&. Reavy, G. (1989). Are androgynous managers really more effective? Group \& Organization Management, 14(2), 234-249. 
Bassoff, E.S., \& Glass, G.V. (1982). The relationship between sex roles and mental health: A meta-analysis of twenty-six studies. Counselling Psychologist, 10, 105-112.

Bem, S. L. (1975). Sex role adaptibility: One consequence of psychological androgyny. Journal of Personality and Social Psychology, 3(4), 634-643.

Bem, S. L. (1981). Gender Schema Theory: A cognitive account of sex-typing Psychological Review, 88(4), 354-364.

Berger, A., \& Krahé, B. (2013). Negative attributes are gendered too: Conceptualizing and measuring positive and negative facets of sex-role identity. European Journa of Social Psychology, 43(6), 516-531.

Bernstein, C. (2013). Sex roles identity and wellbeing. PhD dissertation, Johannesburg, South Africa: University of Witwatersrand.

Borna, S., \& White. G. (2003). Sex and Gender: Two confused and confusing concepts in the women in Corporate Management Literature. Journal of Business Ethics, $47(2), 89-99$.

Burchardt, C.J., \& Serbin, L.A. (1982). Psychological androgyny and personality adjustment in college and psychiatric populations. Sex Roles, 8(8), 835-851.

Castlebury, F.D., \& Durham, T.W. (1997). The MMPI-2 GM and GF scales as measures of psychological well-being. Journal of Clinical Psychology, 53(8), 879-893.

Cheng, C. (2005). Processes underlying gender-role flexibility: Do androgynous individuals know more or know how to cope? Journal of Personality, 73(3), 645-673.

Cook, E. (1985) Psychological androgyny. New York: Pergamon Press.

Dohi, I., Yamada, F., \& Asada, H. (2001). The relationship between masculinity and the type a behavior pattern: The moderating effects of femininity. Japanese type a behavior pattern: The moder
Psychological Research, 43(2), 83-90.

Eagly, A., \& Wood, W. (2012). Social role theory. Handbook of Theories of Social Psychology, 2, 458-476.

Flaherty, J.F., \& Dusek, J.B. (1980). An investigation of the relationship between psychological androgyny and components of self-concept. Journal of Personality and Social Psychology, 38(6), 984-992.

Fritz, H.L., \& Helgeson, V.S. (1998). Distinctions of unmitigated communion from communion: Self-neglect and over-involvement with others. Journal of Personality and Social Psychology, 75(1), 121-140.

Gerdes, L.C., Moore, C., Ochse, R., \& van Ede, D. (1988). The developing adult (2nd edn.). Durban: Butterworths Professional Publishers.

Ghaed, S.G., \& Gallo, L. (2006). Distinctions among agency, communion, and unmitigated agency and communion according to the interpersonal circumplex, five-factor model, and social-emotional correlates. Journal of Personality Assessment, 86(1), 77-88.

Goolsby, J.R., Lagace, R.R., \&. Boorom, M.L. (1992). Psychological adaptiveness and sales performance. Journal of Personal Selling \& Sales Management, 12(2), 51-66.

Guastello, D.D., \& Guastello, S.J. (2003). Androgyny, gender role behavior, and emotional intelligence among college students and their parents. Sex Roles, 49(11-12), 663-673.

Hall, M., Gough, G., \& Seymour-Smith, S. (2012). I'm METRO, NOT Gay!: A discursive analysis of men's accounts of makeup use on YouTube. The Journal of Men's Studies, 20(3), 209-226.

Hanson, G.R., \& Rayman, J. (1976). Validity of sex-balanced interest inventory scales. Journal of Vocational Behavior, 9(3), 279-291.

Hébert, T.P. (2000). Gifted males pursuing careers in elementary education: Factors that influence a belief in self. Journal for the Education of the Gifted, 24(1), 7-45.

Heilman, M.E. (2012). Gender stereotypes and workplace bias. Research in Organisational Behaviour, 32, 113-135.

Helgeson, V.S. (1994). Relation of agency and communion to well-being: Evidence and potential explanations. Psychological Bulletin, 116(3), 412-428.

Helgeson, V.S., \& Fritz, H.L. (1998). A theory of unmitigated communion. Personality and Social Psychology Review, 2(3), 173-183.

Helgeson, V.S., \& Fritz, H.L. (1999). Unmitigated agency and unmitigated communion Distinctions from agency and communion. Journal of Research in Personality, 33(2), 131-158.

Helmreich, R.L., Spence, J.T., \& Wilhelm, J.A. (1981). A psychometric analysis of the Personal Attributes Questionnaire. Sex Roles, 7(11), 1097-1108.

Huck, S. W. (2009). Reading Statistics and Research (5th edn.). Boston: Pearson Education Inc.

Jacobs, S. (2014). Sex role identity and positive psychological constructs among South African employees. Masters dissertation, Johannesburg, South Africa: University of Witwatersrand.

Jagacinski, C.M. (1987). Androgyny in a male-dominated field: The relationship of sextyped traits to performance and satisfaction in engineering. Sex Roles, 17(9-10), 529-547.

Jurma, W.E., \& Powell, M.L. (1994). Perceived gender roles of managers and effective conflict management. Psychological Reports, 74(1), 104-106.

Keller, C.J., Lavish, L., \& Brown, C. (2007). Creative styles and gender roles in undergraduates students. Creativity Research Journal, 19(2-3), 273-280.

Kim, J., \& Mueller, C.W., (1986). Introduction to factor analysis: What it is and how to do it. Sage University paper series on quantitative applications in social sciences. Beverly Hills and London; Sage Publications.

Kopper, B.A., \& Epperson, D. L. (1996). The experience and expression of anger: Relationships with gender, gender role socialization, depression, and mental health functioning. Journal of Counseling Psychology, 43(2), 158.
Lam, C.B., \& McBride-Chang, C.A. (2007). Resilience in young adulthood: The moderating influences of gender-related personality traits and coping flexibility. moderating influences of gende
Sex Roles, 56(3-4), 159-172.

Lassk, F.G., Kennedy, K.N., Powell, C.M., \& Lagace, R.R. (1992). Psychological adaptiveness and sales managers' job performance. Journal of Social Behavior \& Personality, 7(4), 611-620.

Littrell, R.F., \& Nkomo, S. (2005). Gender and race differences in leader behaviour preferences in South Africa. Women in Management Review, 20(8), 562-580.

Lubinski, D., Tellegen, A., \& Butcher, J. (1981). The relationship between androgyny and subjective indicators of emotional well-being. Journal of Personality and Social Psychology, 40, 722-730.

Lubinski, D., Tellegen, A., \& Butcher, J. (1983). Masculinity, femininity, and androgyny viewed and assessed as distinct concepts. Journal of Personality and Social Psychology, 44, 428-439.

Markstrom-Adams, C. (1989). Androgyny and its relation to adolescent psychosocial well-being: A review of the literature. Sex Roles, 21(5-6), 325-340.

Marsh, H., \& Myers, M. (1986). Masculinity, femininity and androgyny: a methodological and theoretical critique. Sex Roles, 14, 397-430.

May, A., \& Spangenberg, J. (1997). Androgyny and coping in men with a manageria orientation. South African Journal of Psychology, 27(4), 244-249.

McCreary, D., \& Korabik, K. (1994). Examining the relationships between the socially desirable and undesirable aspects of agency and communion. Sex Roles, 31(11-12), 637-651.

Murphy, K. R., \& Davidshofer, C.O. (2005). Psychological testing: Principles and testing. Pearson, USA.

Norlander, T., Erixon, A., \& Archer, T. (2000). Psychological androgyny and creativity: Dynamics of gender-role and personality trait. Social Behavior and Personality: An International Journal, 28(5), 423-435.

Nunnally, J. C., \& Bernstein, I. H. (1994). The assessment of reliability. Psychometric theory, 3(1), 248-292.

O'Heron, C., \&. Orlofsky, J. (1990). Stereotypic and non-stereotypic sex role trait and behavior orientations, gender identity, and psychological adjustment. Journal of Personality and Social Psychology, 58(1), 134-143.

Orlofsky, J., \& O'Heron, C.A. (1987). Stereotyping and non-stereotypic sex role trait and behaviour orientations: implications for personal adjustment. Journal of Personality and Social Psychology, 52, 1034-1042.

Park, D. (1997). Androgynous leadership style: An integration rather than a polarization. Leadership \& Organization Development Journal, 18(3), 166-171.

Petry, R.A., \& Thomas, J. (1986). The effect of androgyny on the quality of psychotherapeutic relationships. Psychotherapy: Theory, Research, Practice, Training, 23(2), 249-251.

Powell, G.N., \& Butterfield, D.A. (2015). The role of androgyny in leader prototypes over four decades. Gender in Management: An International Journal, 30(1), 69-86.

Prentice, D., \& Carranza, E. (2002). What women and men should be, shouldn't be, are allowed to be, and don't have to be: The contents of prescriptive gender stereotypes. Psychology of Women Quarterly, 26(4), 269-281.

Rawski, S.L., Djurdjevic, E., \& Sheppard, L.D. (2014). Occupational stress: Considering the complex interplay of sex, gender, and job roles. The Role of Demographics in Occupational Stress and Well Being (Research in Occupational Stress and Well-being, Volume 12) Emerald Group Publishing Limited, 12, 199-233.

Ricciardelli, L., \& Williams, R. (1995). Desirable and undesirable gender traits in three behavioral domains. Sex Roles, 33(9-10), 637-655.

Senneker, P., \& Hendrick, C. (1983). Androgyny and helping behavior. Journal of Personality and Social Psychology, 45(4), 916-925.

Skoe, E. (1995). Sex role orientation and its relationship to the development of identity and moral thought. Scandinavian Journal of Psychology, 36(3), 235-245.

Smiler, A.P. (2006). Conforming to masculine norms: Evidence for validity among adult men and women. Sex Roles, 54(11-12), 767-775.

Snyman, N. (2011). The sex role identities adopted by Black and white working females in South Africa. Masters dissertation. Johannesburg, South Africa: University of the Witwatersrand.

Spence, J., Helmreich, R., \& Holahan, C. (1979). Negative and positive components of psychological masculinity and femininity and their relationships to self-reports of neurotic and acting out behaviors. Journal of Personality and Social Psychology, 37(10), 1673-1682.

Spence, J.T., Helmreich, R.L., \& Stapp, J. (1975). Ratings of self and peers on sex role attributes and their relation to self-esteem and conceptions of masculinity and femininity. Journal of Personality and Social Psychology, 32, 29-39.

Taylor, M., \& Hall, J. (1982). Psychological androgyny: Theories, methods, and conclusions. Psychological Bulletin, 92(2), 347-366.

Vinnicombe, S., \& Singh, V. (2002). Sex role stereotyping and requisites of successful top managers. Women in Management Review, 17(3/4), 120-130.

Wajsblat, L. (2011). Positive androgyny and well-being: A positive psychological perspective on gender role Valence. PhD dissertation. Hempstead, NY: Hofstra University.

West, C., \& Zimmerman, D. (1987). Doing gender. Gender and Society, 1(2), 125-151.

Whitley, B. (1985). Sex-role orientation and psychological well-being: Two metaanalyses. Sex Roles, 12(1-2), 207-225.

Wolfram, H.J., \& Gratton, L. (2014). Gender role self-concept, categorical gender, and transactional-transformational leadership implications for perceived workgroup performance. Journal of Leadership \& Organizational Studies, 21(4), 338-353. 
Woodhill, B., \& Samuels, C. (2003). Positive and negative androgyny and their relationship with psychological health and well-being. Sex Roles, 48(11-12) relationsh 565 .

Woodhill, B., \& Samuels, C. (2004). Desirable and undesirable androgyny: A prescription for the twenty-first century. Journal of Gender Studies, 13(1), $15-28$.
Wulff, M., \& Steitz, J. (1999). A path model of the relationship between career indecision, androgyny, self-efficacy, and self-esteem. Perceptual and Motor Skills, 88(3), 935-940.

Yawn, C. (2007). Socially undesirable gender-linked personality traits and their relation to alcohol abuse in a college population (Doctoral dissertation, Humboldt State University). 